\title{
Frequency of infantile colic in neonates presenting at Tertiary Care Hospital.
}

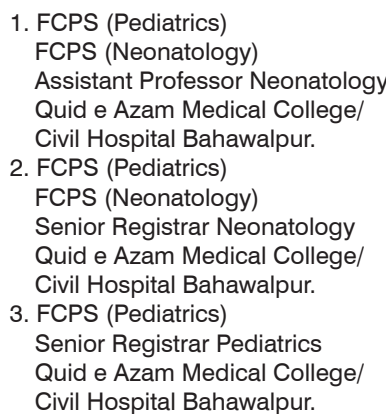

Correspondence Address: Dr. Anwar Muhammad Hafiz Department of Neonatology Quid e Azam Medical College/ Civil Hospital Bahawalpur. hmanwar157@yahoo.com

Article received on: 20/02/2020

Accepted for publication: $15 / 05 / 2020$

\begin{abstract}
Anwar Muhammad', Muhammad Asghar Ali $^{2}$, Ali Hammad ${ }^{3}$
ABSTRACT... Objectives: To determine the frequency of infantile colic in neonates presenting at tertiary care hospital. Study Design: Cross Sectional Study. Setting: Department of Neonatology, Civil Hospital, Bahawalpur. Period: From January 2018 to August 2018. Material \& Methods: Total 467 neonates either male or female were selected for this study. Total 467 neonates with complaints of crying and fussing either male or female were selected for this study and infantile colic was assessed in selected neonates by using Wessel criteria. Results: Total 467 neonates were selected for this study. Mean age of the neonates was $24.94 \pm 2.39$ months, mean gestational age and mean weight was $39.42 \pm 1.22$ weeks and $3.27 \pm 0.62 \mathrm{~g}$ respectively. Infantile colic was found in $322(69 \%)$ neonates. Infantile colic was found in 61 (33.33\%) neonates, $136(94.44 \%)$ neonates, 75 (87.21\%) neonates and 50 (92.59\%) neonates respectively. Statistically significant association between infantile colic and type of feeding with p value 0.000. Infantile colic was found in 147 (84.97\%), 95 (67.86), $62(49.21 \%)$ and 18 (64.29\%) neonates respectively in 37 weeks, 38 weeks, 39 weeks and 40 weeks gestational age group. Statistically insignificant association between infantile colic and gestational age was noted with $p$ value 0.000 . Conclusion: Results of present study showed higher rate of colic in infants. Development of colic was highly associated with gestational age, birth weight and type of feeding. There is no effective medical treatment (like anti-colic and herbal drugs) but alternative measures may relieve or prevent further colic attacks.
\end{abstract}

Key words: $\quad$ Birth Weight, Colic, Gestational Age, Infant.

Article Citation: Hafiz AM, Ali MA, Hammad A. Frequency of infantile colic in neonates presenting at tertiary care hospital. Professional Med J 2020; 27(11):23572362. https://doi.org/10.29309/TPMJ/2020.27.11.4588

\section{INTRODUCTION}

Infantile colic is a communal, self-resolving complaint that can be stressful to parents along with health care system. ${ }^{1}$ It is well defined as episode of irritability, fussing or crying remains for $>3 /$ day, $>3$ days in a week, and prolonged 3 weeks or above. ${ }^{3}$ Episodes often occurs in evening or night times having onset in $1^{\text {st }}$ month of life and wind-up until the infant is 3 - 4 months old. ${ }^{4}$ The prevalence of infantile colic varies from $8 \%$ to $40 \%$. This variation may partly be explained by differences in study design and in the definition of infantile colic. ${ }^{5}$ Sometimes attacks of irritability, crying, or fussing are followed by motor activity, flexure posture of body, abdominal distension and or excessive flatus, beside of all this infants are otherwise healthy and growing well. ${ }^{6}$ Currently no effective treatment is known, many non-pharmacological and pharmacological treatment are in practice. ${ }^{7}$ It is a condition with clear concept but its etiology is idiopathic and voluminous reasons including psychosocial and somatic risk factors have been proposed. ${ }^{8}$

Although many studies showed different risk factors and associations related to parents and baby known to cause infantile colic are many like birth weight and infantile colic have diverging results, complications during labor, type of feeding i.e. formula, mother feedings or cow's milk, gastrointestinal motility, serum high S-motilin in baby, parent smoking, and psychological factors before and after delivery at the time of onset of symptoms, lessening of nutrition during critical stages of organ development influences organ functioning and impaired fetal growth has been associated with a large number of diseases. But none have discussed the association of infantile 
colic with gestational age at the time birth. One hypothesis is that babies born before 39 week are suffering from more colic as compare to babies born at 39 week. This may be due to in vivo gut maturation. Previously this risk factor has not been studied and present study was designed to document and compare the onset of infantile colic in neonatal age with gestation age at birth.

The objective of present study was to find out frequency of infantile colic. Results of present study may help us in early management of these cases. So that their morbidity related to it may decrease.

\section{MATERIAL \& METHODS}

This cross sectional was conducted at Department of Neonatology, Civil Hospital, Bahawalpur from January 2018 to August 2018. Total 467 neonates with complaints of crying and fussing either male or female were selected for this study.

Infants crying due to hunger, diaper changing, fatigue and fever due to any cause were excluded from the study.

Infant's age (in months), gender (Male/female, birth weight (low, normal and large for gestational age, gestational age (weeks), mode of delivery (Vaginal/C-section) were noted in pre-designed proforma. Assessment of infantile colic was done by applying Wessel criteria in term of infantile colic (Yes/No).

\section{Wessel Criterial}

Excessive crying duration $>3$ hours/day, going on $>3$ days/week for 3 weeks, in a 2-16 week, in an otherwise healthy baby.

\section{Birth Weight}

Low birth weight $(<2.5 \mathrm{~kg})$, Normal weight $(2.5$ $4 \mathrm{~kg})$, Large for gestational age $(>4 \mathrm{~kg})$

All the collected was entered in SPSS version 18 and analyzed. Mena and SD was calculated for numerical data like age, gestational age and birth weight. Frequencies were calculated for infantile colic, type of feeding. Stratification was done for age, gestational age, birth weight and type of feeding. Post stratification chi-square test applied to see the effect of these on outcome variable i.e. infantile colic. $P$ value $\leq 0.05$ was considered as statistically significant.

\section{RESULTS}

Total 467 neonates were selected for this study. Mean age of the neonates was $24.94 \pm 2.39$ weeks, mean gestational age and mean weight was $39.42 \pm 1.22$ weeks and $3.27 \pm 0.62 \mathrm{~g}$ respectively. Infantile colic was found in 322 (69\%) neonates. (Figure-1)

Neonates were divided into 4 groups according to gestational age i.e. $37+6$ week, $38+6$ week, $39+6$ week and $40+6$ week. Total 173 (37.04\%) neonates belonged to $37+6$ gestational age group followed by $140(29.98 \%)$ to $38+6$ week gestational age group, $126(26.98 \%)$ to $39+6$ week gestational age group and 28 (5.99\%) neonates belonged to $40+6$ week gestational age group. Infantile colic was found in 147 (84.97\%), 95 (67.86), 62 (49.21\%) and 18 (64.29\%) neonates respectively in $37+6$ week, $38+6$ week, $39+6$ week and $40+6$ week gestational age group. Statistically insignificant association between infantile colic and gestational age was noted with $p$ value 0.000 . (Table-I)

Neonates were divided in 3 weight categories i.e. LBW (low birth weight), normal weight and LGA (large for gestational age). Most (318/68.09\%) of the neonates are born with normal weight and infantile colic was noted in 216 (67.92\%). $95(20.34 \%)$ neonates belonged to LBW group, infantile colic was found in 87 (91.58\%) neonates. In LGA group, there were 54 (11.56\%) neonates and infantile colic was found in 19 (35.19\%). Infantile colic was significantly associated weight group with $p$ value 0.000 . (Table-II)

Cases were divided into 4 groups according to type of feeding i.e. Mother Milk, formula feeding, animal milk feeding and mix feeding. Total 183 (39.19\%) neonates were on mother milk followed by 144 (30.84\%) on formula milk, 86 (18.42\%) on animal milk and 54 (11.56\%) on mix feeding. Infantile colic was found in 61 (33.33\%) neonates, 136 (94.44\%) neonates, 75 (87.21\%) neonates and 
50 (92.59\%) neonates respectively. Statistically significant association between infantile colic and type of feeding with $p$ value 0.000 . (Table-III)

Among the 467 neonates, total 280 (60\%) neonates were delivered vaginally and $\mathrm{C}$-section was performed in 187 (40\%) neonates. Infantile colic was found in 190 (67.86\%) neonates and in $132(70.59 \%)$ neonates respectively delivered vaginally or by $\mathrm{C}$-section. Association of infantile colic with mode of delivery was not statistically significant with $p$ value 0.5423 . (Table-IV)

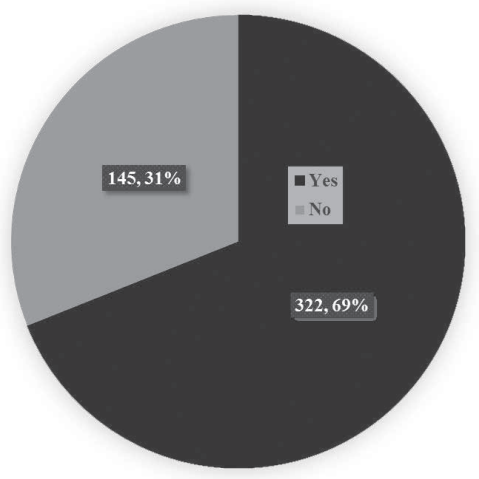

Fig-1: Frequency of infantile colic.

\begin{tabular}{|l|c|c|c|c|}
\hline \multirow{2}{*}{$\begin{array}{c}\text { Gestational Age } \\
\text { Group }\end{array}$} & \multicolumn{2}{|c|}{ Infantile colic } & Total & P-Value \\
\hline $37+6$ & $147(84.97 \%)$ & $26(15.03 \%)$ & $173(37.04 \%)$ & \\
\hline $38+6$ & $95(67.86 \%)$ & $45(32.14 \%)$ & $140(29.98 \%)$ \\
\hline $39+6$ & $62(49.21 \%)$ & $64(50.79 \%)$ & $126(26.98 \%)$ & \multirow{2}{*}{0.000} \\
\hline $40+6$ & $18(64.29 \%)$ & $10(35.71 \%)$ & $28(5.99 \%)$ \\
\hline Total & $322(69 \%)$ & $145(31 \%)$ & 467 \\
\hline
\end{tabular}

\begin{tabular}{|c|c|c|c|c|}
\hline \multirow{2}{*}{ Birth Weight Group } & \multicolumn{2}{|c|}{ Infantile Colic } & \multirow{2}{*}{ Total } & \multirow{2}{*}{ P-Value } \\
\hline & Yes & No & & \\
\hline LBW & 87 (91.58\%) & 8 (8.42\%) & 95 (20.34\%) & \multirow{4}{*}{0.000} \\
\hline Normal & $216(67.92 \%)$ & $102(32.08 \%)$ & 318 (68.09\%) & \\
\hline LGA & 19 (35.19\%) & 35 (64.81\%) & 54 (11.56\%) & \\
\hline Total & 322 (69\%) & 145 (31\%) & 467 & \\
\hline
\end{tabular}

\begin{tabular}{|c|c|c|c|c|}
\hline \multirow{2}{*}{ Type of Feeding } & \multicolumn{2}{|c|}{ Infantile Colic } & \multirow{2}{*}{ Total } & \multirow{2}{*}{ P-Value } \\
\hline & Yes & No & & \\
\hline Mother' Milk Feeding & $61(33.33 \%)$ & $122(66.67 \%)$ & $183(39.19 \%)$ & \multirow{5}{*}{0.000} \\
\hline Formula Milk Feeding & $136(94.44 \%)$ & $8(5.56 \%)$ & $144(30.84 \%)$ & \\
\hline Animal Milk Feeding & 75 (87.21\%) & $11(12.79 \%)$ & $86(18.42 \%)$ & \\
\hline Mix Milk Feeding & 50 (92.59\%) & $4(7.41 \%)$ & $54(11.56 \%)$ & \\
\hline Total & $322(69 \%)$ & $145(31 \%)$ & 467 & \\
\hline
\end{tabular}

\begin{tabular}{|c|c|c|c|c|}
\hline \multirow{2}{*}{ Mode of Delivery } & \multicolumn{2}{|c|}{ Infantile Colic } & \multirow{2}{*}{ Total } & \multirow{2}{*}{ P-Value } \\
\hline & Yes & No & & \\
\hline Vaginal & 190 (67.86\%) & 90 (32.14\%) & $280(60 \%)$ & \multirow{3}{*}{0.5423} \\
\hline C-section & 132 (70.59\%) & 55 (29.41\%) & $187(40 \%)$ & \\
\hline Total & $322(69 \%)$ & 145 (31\%) & 467 & \\
\hline
\end{tabular}




\section{DISCUSSION}

Kolon or kolikos are greek words used for infantile colic, it is a behavioral syndrome including increased crying without a known reason which usually occurs in evening. ${ }^{9}$

The definition of infantile colic given by Wessel et al, based on the characteristic of crying, following the rule of 3 , is the most widely used which is; episodes of excessive crying which lasts $>3$ hours daily, occurring thrice a week for 3 weeks, in a 2 to 16 weeks infant, in an otherwise healthy baby. $^{3}$

Infantile Colic is a benign self-limited condition that resolves with time, but is one of the commonest reasons of seeking medical advice in the first 3-4 months of life. Duration of the colic may last from a few minutes to three hours or more. The crying begins suddenly without any clear reason and is intense and high pitched. There may be flushing of face, postural changes like clenched fist, tense abdomen and is extremely difficult to comfort the baby during the episodes. ${ }^{10}$

The objective of present study was to assess the frequency of infantile colic in neonates.

Total 467 neonates were selected for this study. Mean age of the neonates was $24.94 \pm 2.39$ weeks, mean gestational age and mean weight was $39.42 \pm 1.22$ weeks and $3.27 \pm 0.62 \mathrm{~g}$ respectively. Infantile colic was found in 322 (69\%) neonates.

Prevalence of infantile colic varying from $5-25 \%$ globally. ${ }^{11-12}$ In one study conducted in Turkey ${ }^{13}$, according to mothers' statements, $75.8 \%$ of the babies had colic, while according to the Wessel criteria, $51.1 \%$ had colic symptoms which are similar to our findings. Laila et $\mathrm{al}^{14}$ reported incidence of infantile colic as $48 \%$ in first 3 months of age which is not in agreement with our findings. In another study by Al Saadoon et $\mathrm{al}^{15}$ and Fazil et al ${ }^{16}$ total $14.30 \%$ and $21.77 \%$ neonates had colic which is not in agreement with our findings. Possible reason may be smaller number of sample size.
In two studies conducted in India and Brazil, reported prevalence of infantile colic was $16 \%$ and $16.3 \%$ respectively. ${ }^{17-18}$ Talachian et $\mathrm{al}^{19}$ studied 413 infants for infantile colic, they found $20.4 \%$ infants with colic. In one study by Saavedra et al, only $16.3 \%$ infants meet the Wessel criteria for colic. ${ }^{20} \mathrm{Nam}$ et al ${ }^{21}$ found $36.1 \%$ infants with colic in their study.

In present study infantile colic was found in 147 (84.97\%), 95 (67.86), 62 (49.21\%) and 18 $(64.29 \%)$ neonates respectively in 37 weeks, 38 weeks, 39 weeks and 40 weeks gestational age group. Statistically insignificant association between infantile colic and gestational age was noted with $p$ value 0.000 . Nam et $a^{21}$ reported statistically significant $(P<0.001)$ association between gestational age and development of colic which is in favor of our findings.

Neonates were divided in 3 weight categories i.e. LBW (low birth weight), normal weight and LGA (large for gestational age). Mostly 68.09\% (318) of the neonates are born with normal weight and infantile colic was noted in $67.92 \%$ (216). $20.34 \%$ (95) neonates were LBW and $91.58 \%$ (87) neonates were suffered from infantile colic. Nam et $\mathrm{al}^{21}$ and Søndergaard et $\mathrm{al}^{8}$ reported that prevalence of colic was higher in infants born with a birth weight $<2.5 \mathrm{~kg}(62.7 \%$ vs. $24.4 \%, P<0.001)$ and $10.9 \%$ neonates i.e. had more than twice the risk (odds ratio $=2.7$ ) in infants small for their gestational age, in the $<10$ th percentile $(54.5 \%$ vs. $33.7 \%, P=0.003)$. A similar observation has been observed in our study that LBW babies more suffer from infantile colic i.e. infantile colic was found in $87(91.58 \%)$ neonates. In LGA group consisted of $11.56 \%$ (54) neonates and among them $35.19 \%$ (19) neonates suffered from infantile colic. Infantile colic was significantly associated with this weight group with $p$ value 0.000 while Al Saadoon et $\mathrm{al}^{15}$ and Fazil et $\mathrm{al}^{16}$ found no significant association between infantile colic and neonate's birth weight.

The use of cow's milk in infant feeding is less than 100 years old, and a large number of adverse effects have been described, one adverse effect might be infant colic. Whether 
cow's milk intolerance is due to lactose or protein intolerance is not clear. Colic also occurs in breast-fed babies and seems to be as common as artificial fed infant. ${ }^{22}$ This fact does not exclude diet as a possible cause of infant colic, several maternal foods can cause reactions in breastfed infants, and cow's milk is the commonest. ${ }^{22}$ In present study, total $39.19 \%$ (183) neonates were on exclusive mother milk followed by $30.84 \%$ (144) on formula milk, $18.42 \%$ (86) on animal milk and $11.56 \%$ (54) were on mix milk. Neonates suffered from infantile colic were $33.33 \%(61)$, neonates, $94.44 \%$ (136) neonates, $87.21 \%$ (75) neonates and $92.59 \%$ (50) neonates respectively. Statistically significant association between infantile colic and type of feeding with $p$ value 0.000 . Laila et $\mathrm{al}^{14}$ described that $62 \%$ neonates were suffered from infantile colic which were not on mother milk. While Saavedra et $\mathrm{al}^{20}$ stated that neonates on breast feeding have three time less chance of infantile colic as compared to neonates on formula or cow milk and a similar observation has been found in our study i.e. 33.33\% neonates suffered from infantile colic. The prevalence of colic was significantly different according to the type of feeding $(P=0.001)$, being the lowest in breast-only feeding (29.8\%), $32.8 \%$ in mixed feeding with breast milk and formula, and $49.7 \%$ in formula only feeding.

\section{CONCLUSION}

Results of present study showed higher rate of infantile colic in neonates. Development of infantile colic was highly associated with gestational age, birth weight and type of feeding. There is no effective medical treatment (like anticolic and herbal drugs) but alternative measures may relieve or prevent further colic attacks.

Copyright@ 15 May, 2020.

\section{REFERENCES}

1. Lucassen PL, Assendelft WJ, Van Eijk JT, Gubbels JW, Douwes AC, Van Geldrop WJ. Systematic review of the occurrence of infantile colic in the community. Archives of disease in childhood. 2001 May 1; 84(5):398403.

2. THOMAS DB. Aetiological associations in infantile colic: An hypothesis. Journal of Paediatrics and Child Health. 1981 Dec; 17(4):292-5.
3. Wessel MA, Cobb JC, Jackson EB et al. Paroxismal fussing in infancy, sometimes called "colic." Pediatrics 1954 Nov; 14(5):421-35.

4. Savino F. Focus on infantile colic. Acta paediatrica. 2007 Sep; 96(9):1259-64.

5. Vandenplas $Y$, Abkari A, Bellaiche $M$, Benninga $M$, Chouraqui JP, ÇokuĐrap F, Harb T, Hegar B, Lifschitz C, Ludwig T, Miqdady M. Prevalence and health outcomes of functional gastrointestinal symptoms in infants from birth to 12 months of age. Journal of pediatric gastroenterology and nutrition. 2015 Nov; $61(5): 531$.

6. Hiscock H, Cook F, Bayer J, Le HN, Mensah F, Cann W, Symon B, St James-Roberts I. Preventing early infant sleep and crying problems and postnatal depression: A randomized trial. Pediatrics. 2014 Feb $1 ; 133(2): e 346-54$.

7. Savino F, Ceratto S, De Marco A, di Montezemolo LC. Looking for new treatments of infantile colic. Italian journal of pediatrics. $2014 \mathrm{Dec} 1 ; 40(1): 53$.

8. Søndergaard C, Skajaa E, Henriksen TB. Fetal growth and infantile colic. Archives of Disease in ChildhoodFetal and Neonatal Edition. 2000 Jul 1; 83(1):F44-7.

9. Kheir $A E$. Retracted article: Infantile colic, facts and fiction. Italian journal of pediatrics. 2012 Dec 1; 38(1):34.

10. Savino F. Focus on infantile colic. Acta paediatrica. 2007 Sep; 96(9):1259-64.

11. Lucassen PL, Assendelft WJ, VanFijk H, Gubbls JW, Douwes AC, Van Geldrop WJ. Systematic review of the occurrence of the infantile colic in the community. Arch Dis child 2001; 84:398-403.

12. Clifford TJ, Campbell MK, Speechley KN, Gorodzinsky $F$ : Sequence of infant colic evidence of transient infant distress and absence of lasting effects on maternal mental health. Arch Pediatr Adolesc Med 2002; 156:1183-8.

13. Çiftçi EK, Arikan D. Methods used to eliminate colic in infants in the eastern parts of Turkey. Public Health Nursing. 2007 Nov; 24(6):503-10.

14. Laila SZ, Beauty AA, Hasan MM, Khan MM. Infantile colic: Incidence and effectiveness of conventional therapy. Journal of Armed Forces Medical College, Bangladesh. 2016 Jan 24; 12(1):83-7.

15. Al Saadoon M, Rizvi S, Khan I, Shuaili AK, Mamari MA. Prevalence and Associated Factors of Infantile Colic among Omani Babies. Clin Res Open Access. 2018;4(3). doi.org/10.16966/2469-6714.139 
16. Fazil M. Prevalence and risk factors for infantile colic in District Mansehra. Journal of Ayub Medical College Abbottabad. 2011 Jun 1; 23(2):115-7.

17. Garg P. Infantile colic-unfolded. Indian J Pediatr 2004; 71:903-6.

18. Garg P. Prevalence of infantile colic at a secondary level hospital. Indian Pediatr 2004; 71.1039.

19. Talachian E, Bidari A, Rezaie MH. Incidence and risk factors for infantile colic in Iranian infants. World journal of gastroenterology: WJG. 2008 Aug 7; 14(29):4662.
20. Saavedra MA, Costa JS, Garcias G, Horta BL, Tomasi $E$, Mendonça $R$. Incidência de cólica no lactente e fatores associados: Um estudo de coorte. Jornal de pediatria. 2003 Apr; 79(2):115-22.

21. Nam SK, Park S, Lee J, Jun YH. Clinical characteristics of infantile colic. Neonatal Medicine. 2019 Feb 28; 26(1):34-40.

22. Chalabi D, Omer K, Al-Tawil N. Risk factors for infantile colic: A case control study. 2016 Jan 1; 1717.

\begin{tabular}{|c|c|c|c|}
\hline \multicolumn{4}{|c|}{ AUTHORSHIP AND CONTRIBUTION DECLARATION } \\
\hline Sr. \# & Author(s) Full Name & \multicolumn{1}{|c|}{ Contribution to the paper } & Author(s) Signature \\
\hline 1 & Anwar Muhammad & $\begin{array}{l}\text { Manuscript writing, Data collection, Data } \\
\text { entry, Analysis and proof reading. }\end{array}$ \\
\hline 2 & M. Asghar Ali & $\begin{array}{l}\text { Data collection, data entry, Review } \\
\text { research, Proof reading. } \\
\text { Data collection, Data entry, Review } \\
\text { research, Proof reading. }\end{array}$ \\
\hline 3 & Ali Hammad & \\
\hline
\end{tabular}

